\title{
ADMINISTRATIVE REFORM AND ORGANIZATIONAL CHANGE AT AGRICULTURAL EXTENSION ORGANIZATIONS: A LONGITUDINAL STUDY OF CENTRAL ADMINISTRATION OF AGRICULTURAL EXTENSION
}

Kassem, H. S.

Agric. Extension and Rural Society Dept., Faculty of Agric., Mansoura Univ., Egypt

الإصلاح الإدارى والتغيير التنظيمى بالمنظمـات الإرشـادية الزراعية: دراسـة تتبعيـة

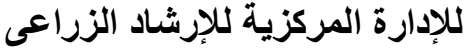

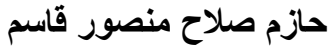
قسم الإرشاد الزراعى والمجتمع الريفى، كلية الزراعة، جامعة المنصورة

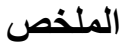

استهافت هذه الدراسة قياس مقدار التطور و التغير الذي طر أ بفعل عامل الزمن على الزع أداء الإدارة المركزيـة

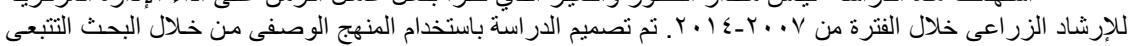

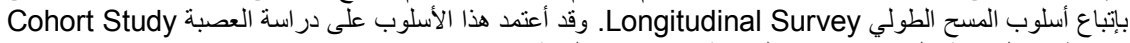

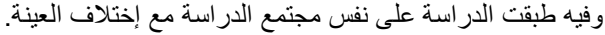

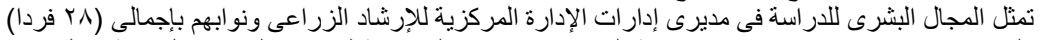

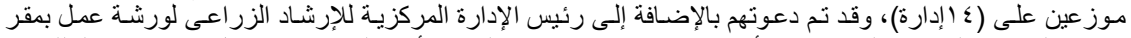

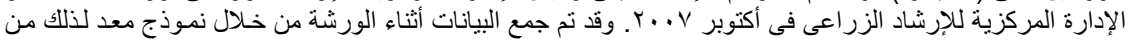

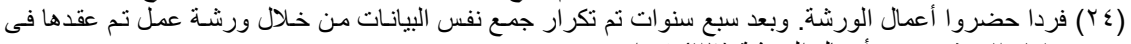

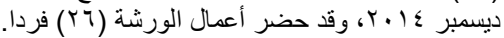

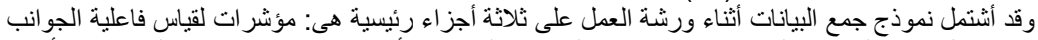

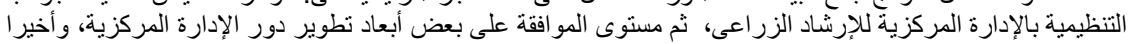

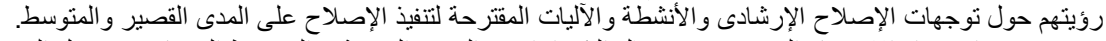

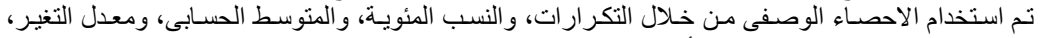

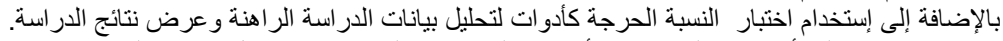

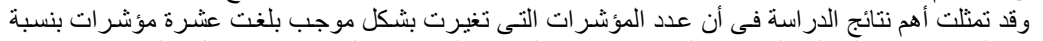

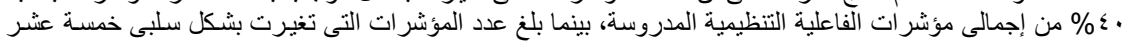

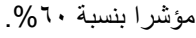

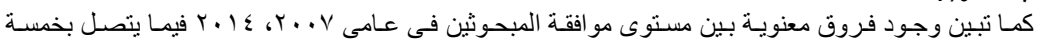

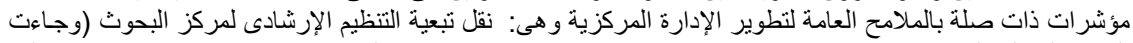

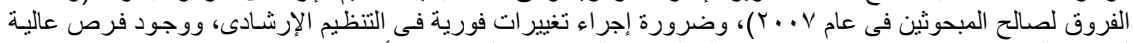

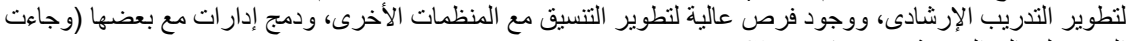

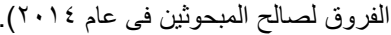

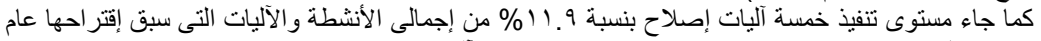

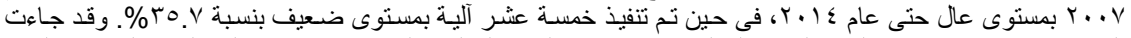

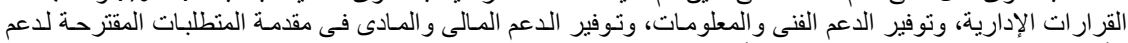

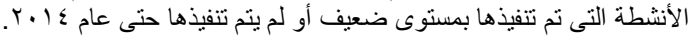

\section{المقدمة}

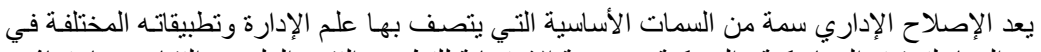

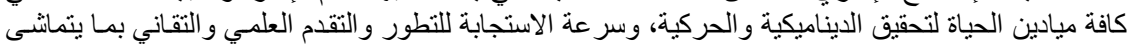

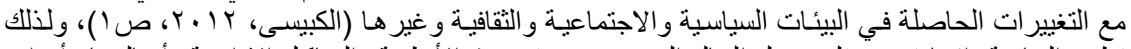

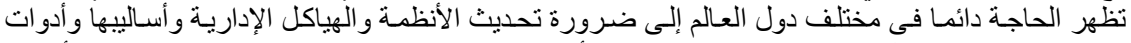

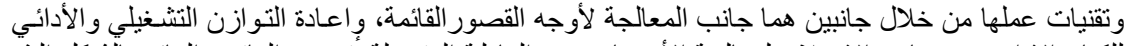

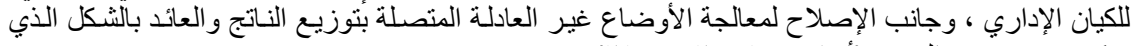

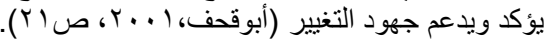




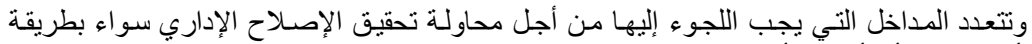

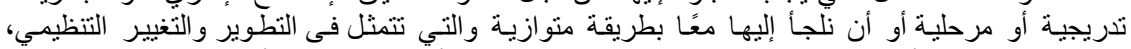

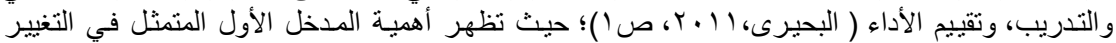

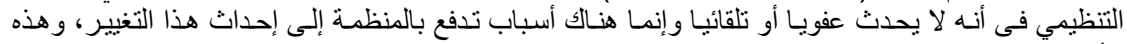

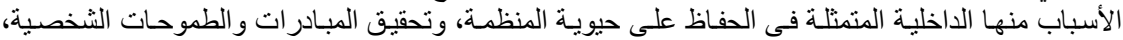

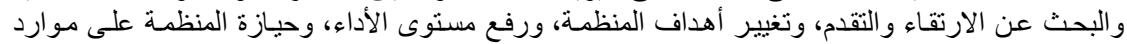

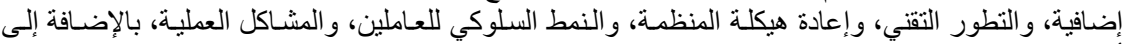

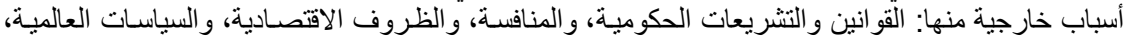

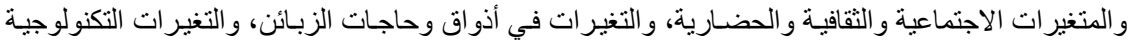

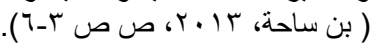

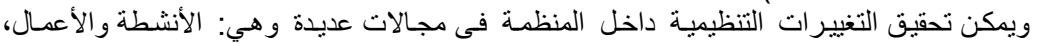

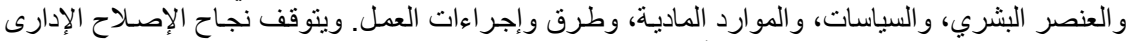

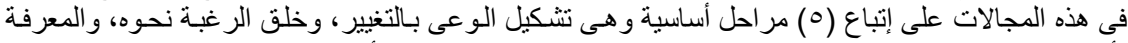

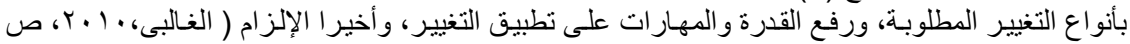

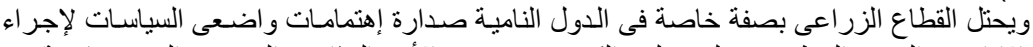

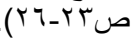

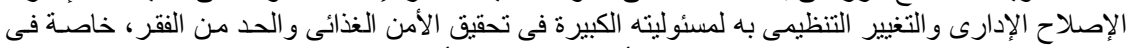

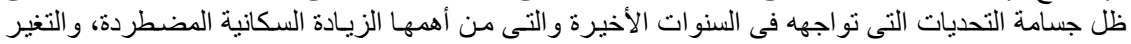

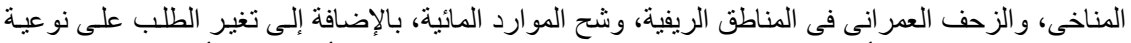

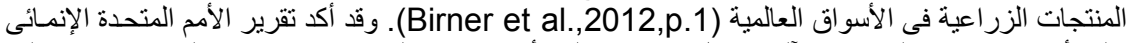

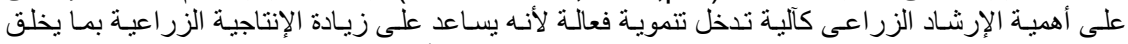

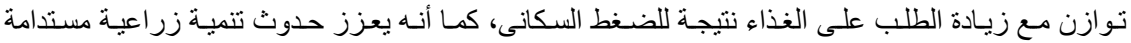

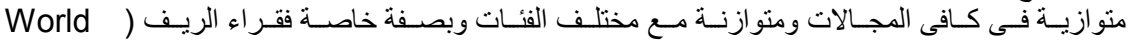

(Bank,2007,pp.5-6

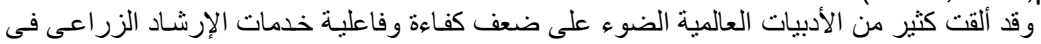

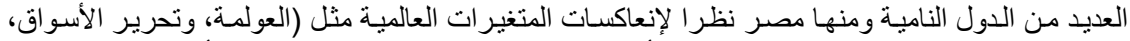

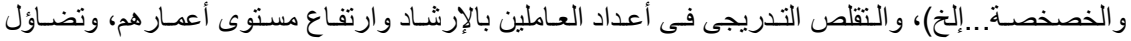

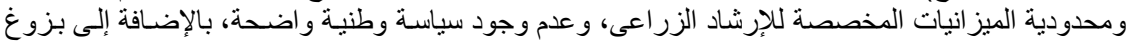

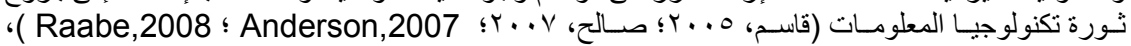

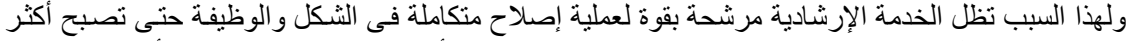

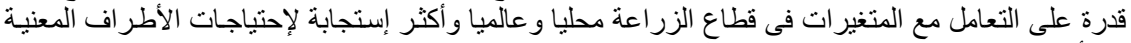

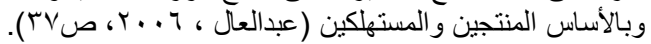

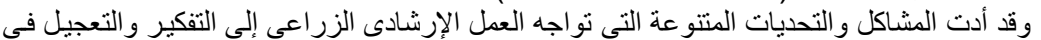

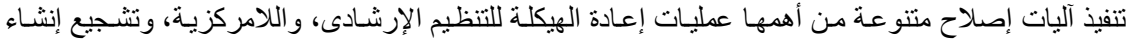

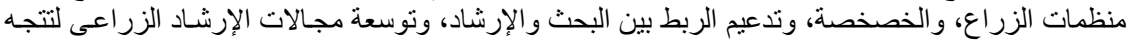

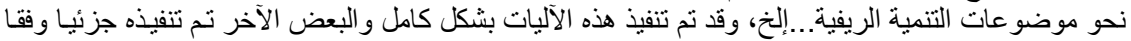

لطبيعة السياق فى كل دولة (Feder et al.,2011,p.1). وقد استخلصت در اسـة (2006,p.12) أحد أهم الدروس المستفادة نتيجة تطبيق

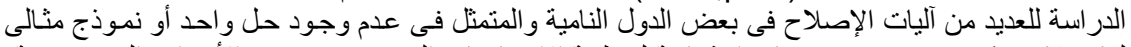

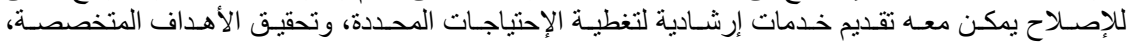

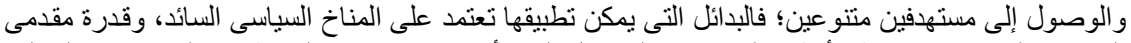

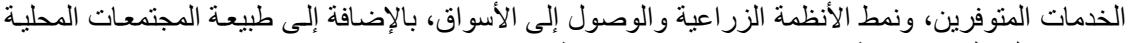

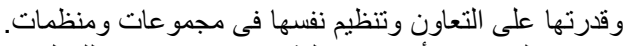

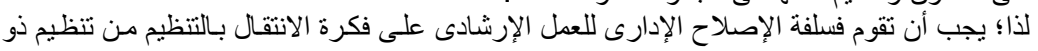

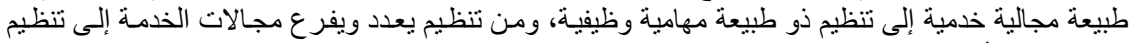

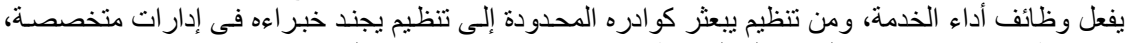

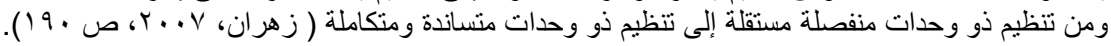




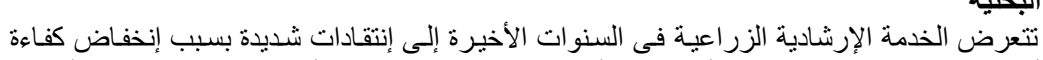

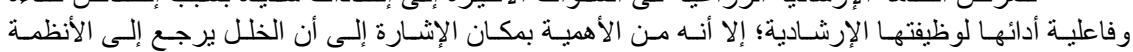

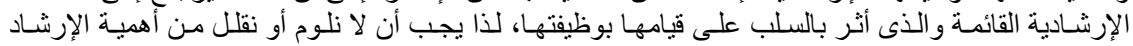

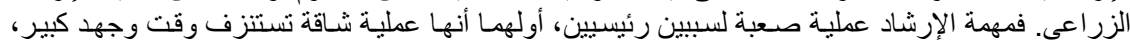

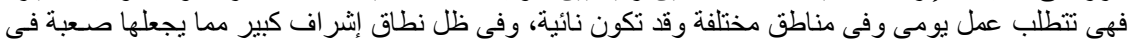

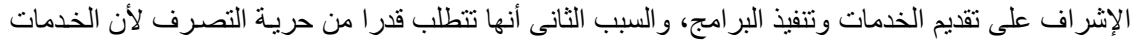

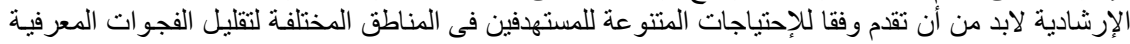
و التنفيذية لديهم.

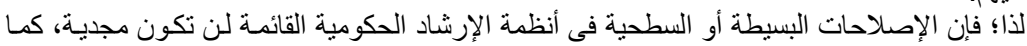

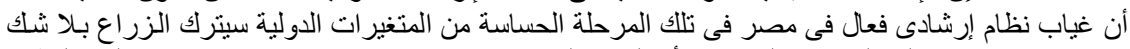

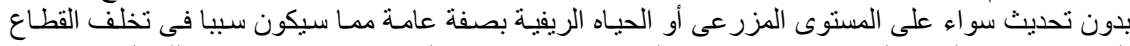

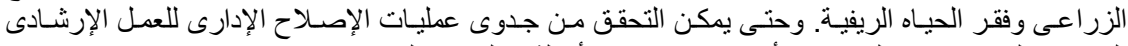

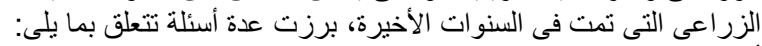

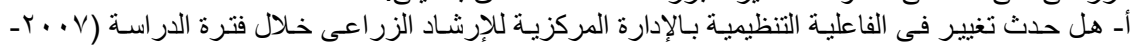
$\varphi(T \cdot) \leq$

بـ ما هى مستوى مو افقة المبحوثين على الأبعاد المختلفة لتطوير منظومـة العمل الإرشـادى الزراعى؟ وهل

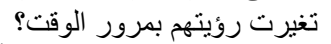

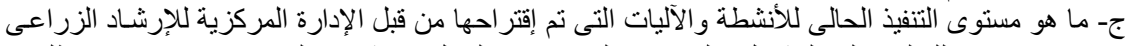

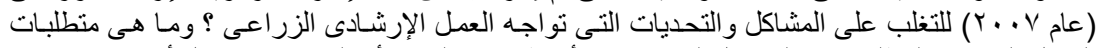

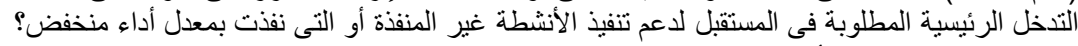

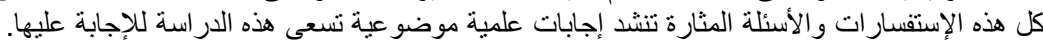

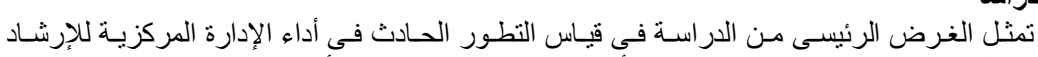
أهداف الدراسة الأة

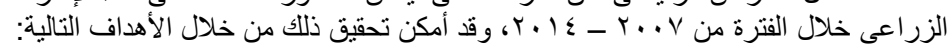

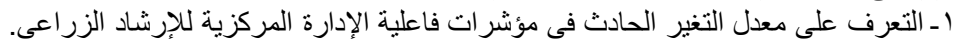

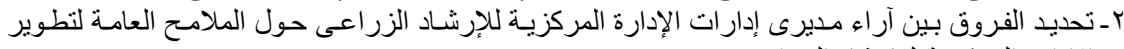

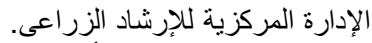

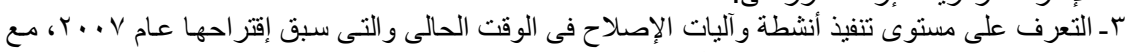
تحديد متطلبات دعم تنفيذها فى المستقبل.

\section{الطريقة البحثية}

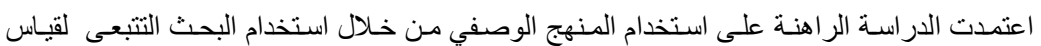

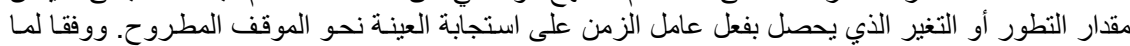
أورده (2001, Rajulton ) يمكن تطبيق البحث التنبعي بأحد الأسلوبين التاليين:

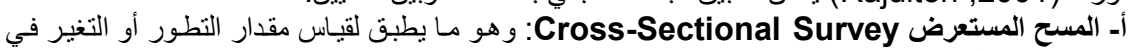

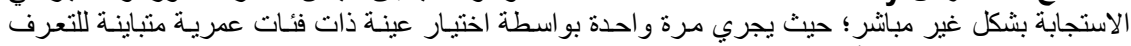

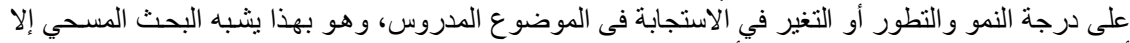

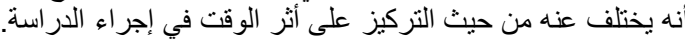

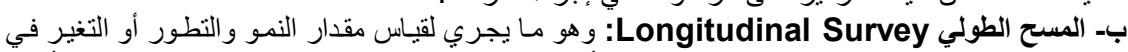

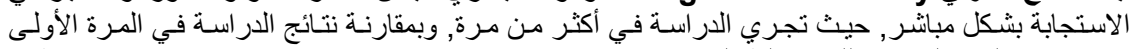

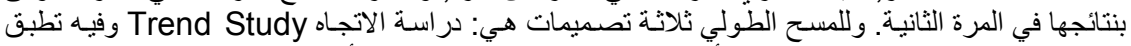

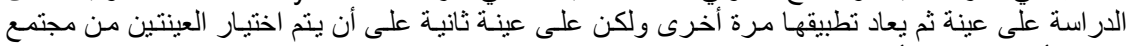

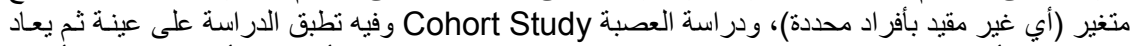

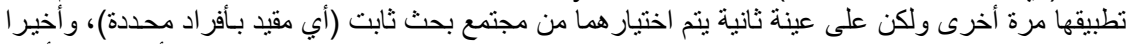

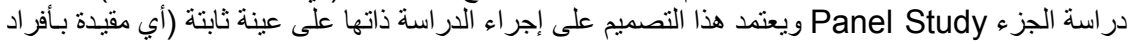


Kassem, H. S.

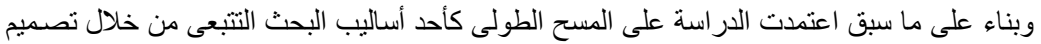

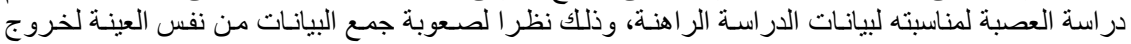
معظمه على المعاش.

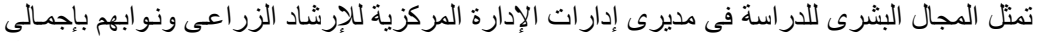

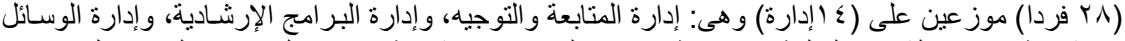

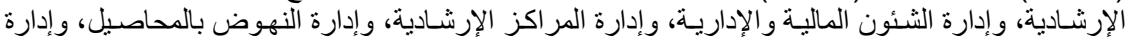

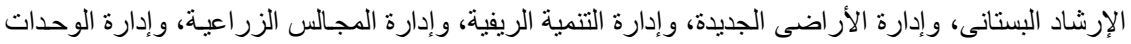

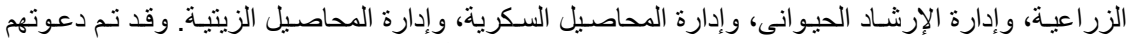

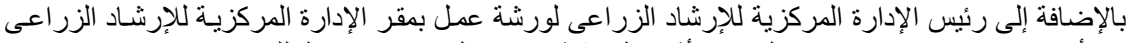

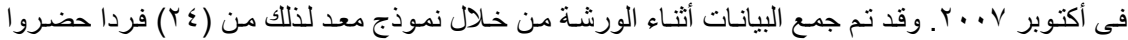

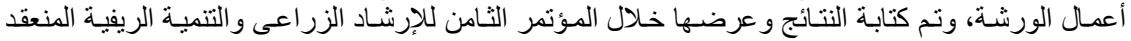

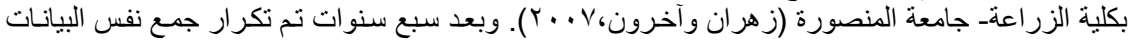

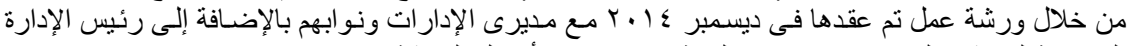

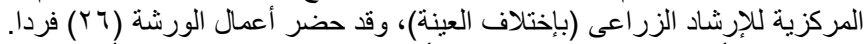

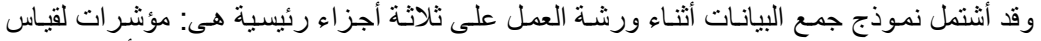

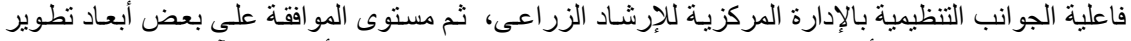

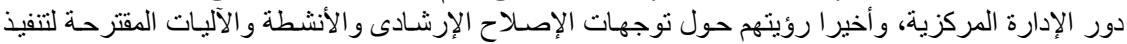

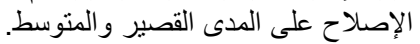

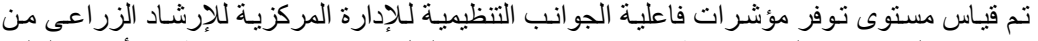

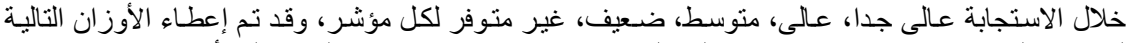

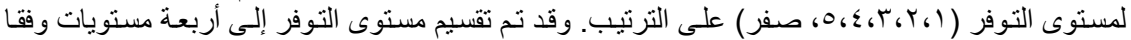

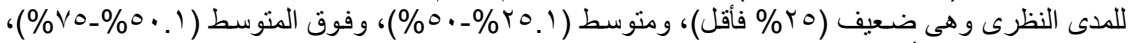

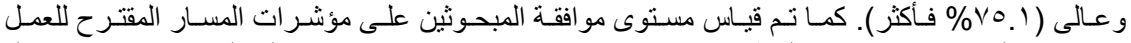

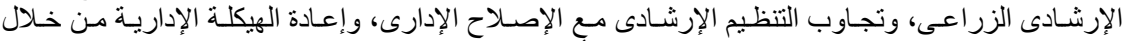

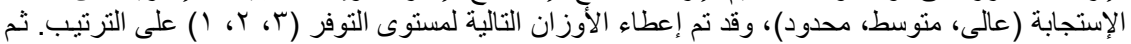

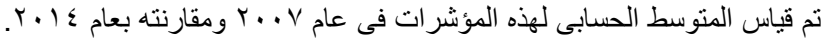

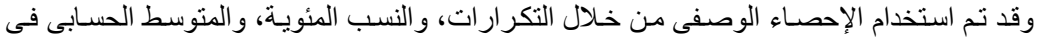

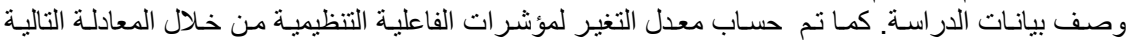

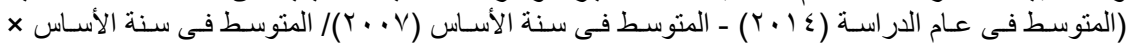

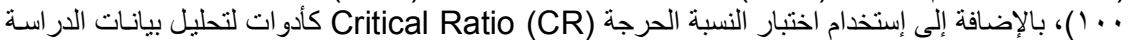
الر اهنة و برض نتائج الدراسة.

\section{(لنتائتج}

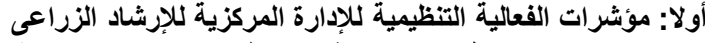

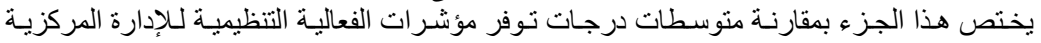

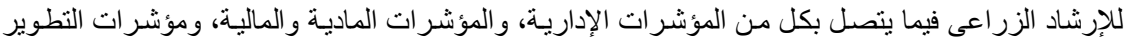

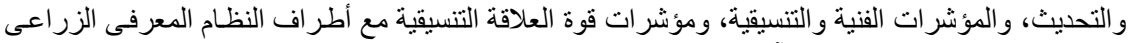

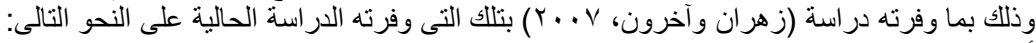

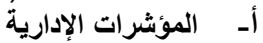

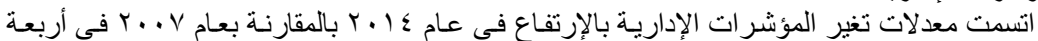

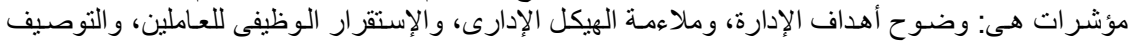

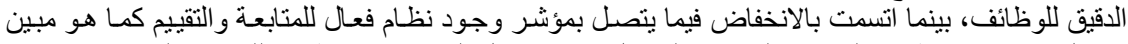

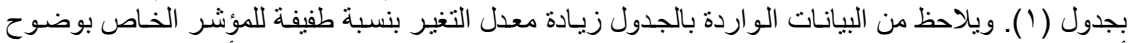

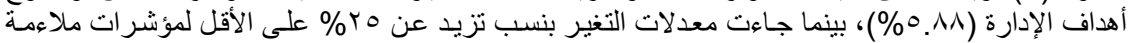

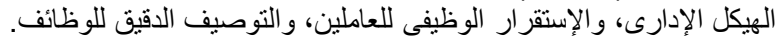




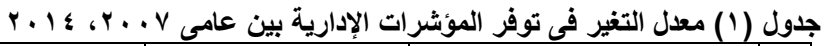

\begin{tabular}{|c|c|c|c|c|c|c|}
\hline \multirow[b]{2}{*}{ معدل التغير } & \multicolumn{2}{|c|}{ 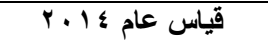 } & \multicolumn{2}{|c|}{ قياس عام V. V. F } & \multirow{2}{*}{ المؤشرات الإدارية } & \multirow[b]{2}{*}{ b } \\
\hline & المستوى & المتوسط & المستوي & المتوسط & & \\
\hline $0 . \wedge \wedge+$ & عالى & 人) & عالى & $V 7.0$ & وضو لوض أهـــــــاف الإدارة. & 1 \\
\hline $0 . V \leqslant+$ & فوق المتوسط & (1) & متو سط & $\sum V_{.1}$ & ملاءمة الهيكل الداخل ـــي. & r \\
\hline rᄉ.YI+ & فوق منوسط & 70.1 & متوسط & $\sum V_{.1}$ & الاستقرار الوظبفى للعاملين. & $r$ \\
\hline ro.r+ & متوسط & $\varepsilon \varepsilon, Y$ & متو سط & ro.r & التوصيف الدقيق للوظائف. & $\varepsilon$ \\
\hline$r \leqslant .1 T-$ & فوق المتوسط & 70.1 & s & ᄉ०. $\wedge$ & 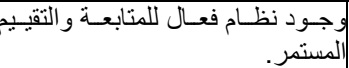 & 0 \\
\hline
\end{tabular}

ب-المؤشرات المادية والمالية

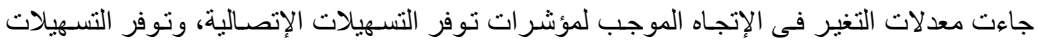

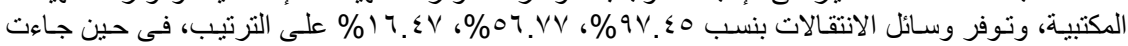

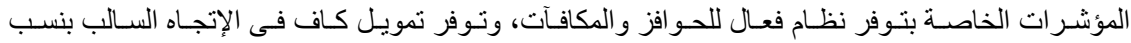

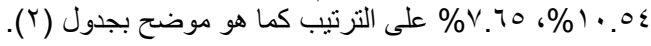

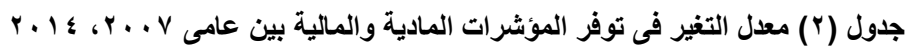

\begin{tabular}{|c|c|c|c|c|c|c|}
\hline \multirow{2}{*}{ معدل التغير } & \multicolumn{2}{|c|}{ قياس عام ؛ I +. } & \multicolumn{2}{|c|}{ قياس عام V.... } & \multirow{2}{*}{ المؤشرات المادية والمالية } & \multirow[b]{2}{*}{ p } \\
\hline & المستوى & المتوسط & المستوى & المتوسط & & \\
\hline V.70- & ضعيف & YI.V & ضعيف & Tr.o & توفر تمويل كاف. & 1 \\
\hline $07 . V V+$ & ضعيف & 11.0 & ضعيف & 11.1 & توفر التسهيلات المكتبيـة. & r \\
\hline $9 V . \leqslant 0+$ & ضعيف & rt.r & ضعيف & 11.1 & توفر التسهيلات الاتصالية. & $r$ \\
\hline $17 . \leqslant V+$ & ضعيف & $r \cdot .0$ & ضعيف & $1 V .7$ & توفر وسائل الانتقة ــالات. & $\varepsilon$ \\
\hline $1 \cdot .0 \leq-$ & منوسط & rY.r & متوسط & rq. & توفر نظام فعال للحو افز و المكافآت. & 0 \\
\hline
\end{tabular}

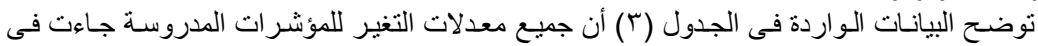

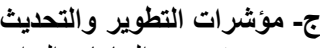

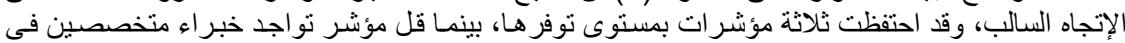

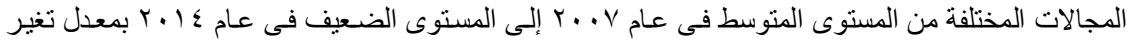

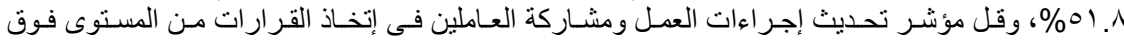

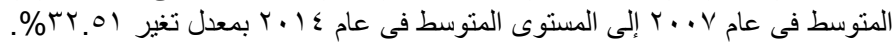

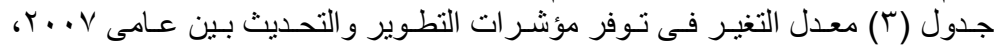

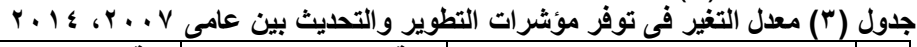

\begin{tabular}{|c|c|c|c|c|c|c|}
\hline \multirow{2}{*}{ ت بعدل التغير } & \multicolumn{2}{|c|}{ قياس عام ؟ 1 +. } & \multicolumn{2}{|c|}{ 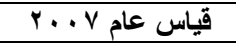 } & \multirow{2}{*}{ مؤشرات التطوير والتحديث } & \multirow[b]{2}{*}{ p } \\
\hline & المستوى & المتوسط & المستوى & المتوسط & & \\
\hline$r .7-$ & متوسط & rA. ${ }^{\circ}$ & متوسط & rq.ร & تدريب إرشادى / فنى دورى. & 1 \\
\hline $1 \cdot .74-$ & 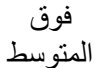 & or.1 & 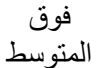 & $0 \wedge . r$ & التطوير المستمر فى محتوى البر امج. & r \\
\hline $01 . \wedge-$ & ضعيف & KY.V & منوسط & $\left.\leqslant V_{.}\right)$ & تو اجد خبر اء متخصصين فى المجالات & $r$ \\
\hline r. & ضعيف & $11 . \wedge$ & ضعيف & rT.o & استخدام وسائل الإتصات الحديثة فى الخدات. & $\varepsilon$ \\
\hline Tr.01 - & متوسط & ro.V & المتوسط & or. 9 & تحديث إجر اءات العمل ومشاركة إتخاذ القرات & 0 \\
\hline
\end{tabular}


د- المؤشرات الفنية والتنسيقية

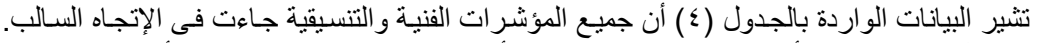

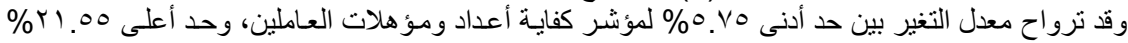

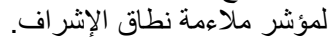

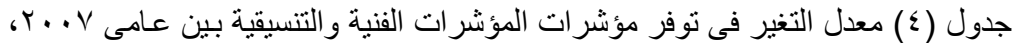

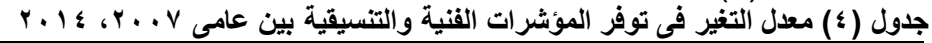

\begin{tabular}{|c|c|c|c|c|c|c|}
\hline \multirow{2}{*}{ معدل التغير } & \multicolumn{2}{|c|}{ 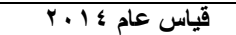 } & \multicolumn{2}{|c|}{ 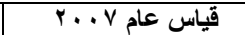 } & \multirow{2}{*}{ المؤشرات الفنية والتتسيقية } & \multirow[b]{2}{*}{ p } \\
\hline & 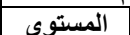 & المتوسط & 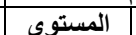 & المتوسط & & \\
\hline $0.10-$ & 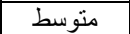 & TV.A & 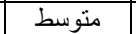 & rq. ६ & كفاية أعداد ومؤهلات العاملين. & 1 \\
\hline Y1.00 - & 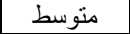 & $\leqslant 1.0$ & |فوق المتوسط| & 0 or. 9 & ملاءمة نطاق الإشراف. & r \\
\hline $17.10-$ & فوق المتوسط| & $0 \wedge . \mathrm{V}$ & |فوق المتوسط| - ما & $v \cdot .7$ & سيادة العمل الفريقى متكامل الخبرات & r \\
\hline $11 . \cdot \leq-$ & فوق المتوسط & $T Y . \wedge$ & |فوق المتوسط & $V \cdot .1$ & العلاقة التنسيقية مع المستويات العليا. & $\varepsilon$ \\
\hline $1 \leqslant .7 \leqslant-$ & فوق المتوسط & 70.4 & عالى & 17.0 & العلاقة التنسيقية مع المستو يات الأدنى. & 0 \\
\hline
\end{tabular}

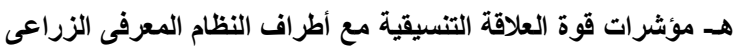

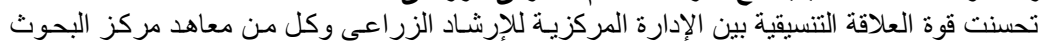

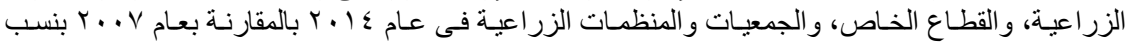

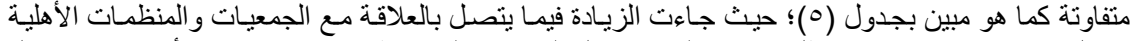

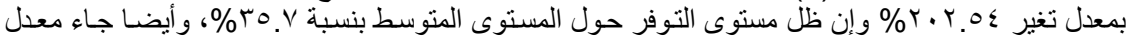

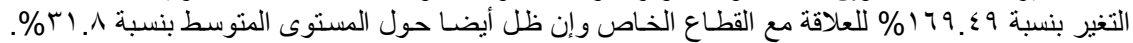

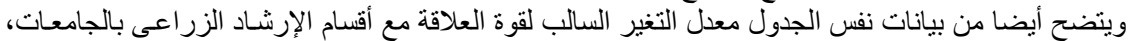

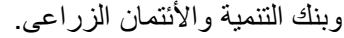

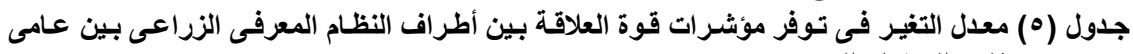
r. $1 \leq$ ، r...V

\begin{tabular}{|c|c|c|c|c|c|c|}
\hline \multirow{2}{*}{ معدل التغير } & \multicolumn{2}{|c|}{ قياس عام \& I +. } & \multicolumn{2}{|c|}{ قياس عام V ... } & \multirow{2}{*}{ مؤشر ات قوة العلاقة مع أطراف النظام الزعى المعى الزرام } & \multirow[b]{2}{*}{ p } \\
\hline & المستوى & المتوسط & المستوى & المتوسط & & \\
\hline$r . Y Y+$ & عالى & $\forall \wedge . Y$ & عالى & $V 7.0$ & العلاقة التنسيقية مع معاهد مركز الزراعة & 1 \\
\hline Q.rr $=$ & متوسط & rV. & متوسط & $\leqslant 1 . r$ & العلاقة التنسيقية مع أقسام الإرشاد & r \\
\hline $179 . \leqslant 9+$ & متوسط & r. & ضعيف & 11.1 & 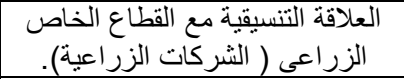 & r \\
\hline r. r.O $0 \varepsilon+$ & متوسط & ro.V & ضعيف & 11.1 & العلاقة التنسيقية مع الجمعيات المنية. & $\varepsilon$ \\
\hline rT.OV - & ضعيف & 11.1 & ضعيف & $Y \leq .7$ & العلافة التنسيقية مع بنك التنمبة التية & 0 \\
\hline
\end{tabular}

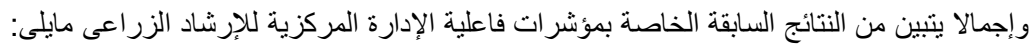

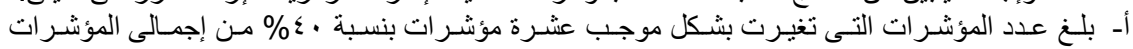

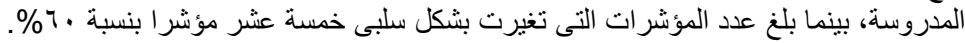

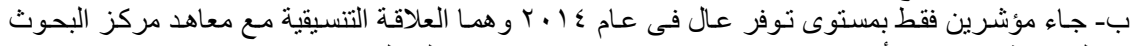

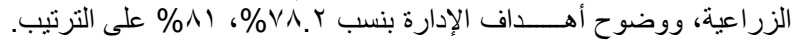

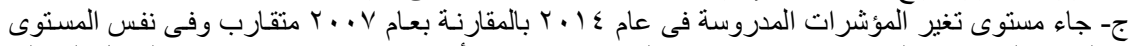

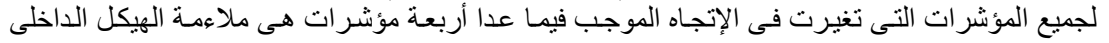

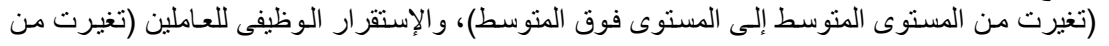




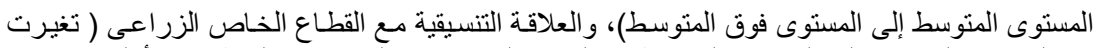

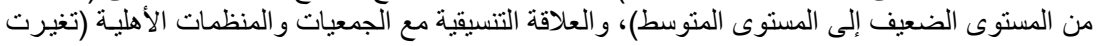
من المستوى الضعيف إلى المستى المستوى المتوى المتوسط).

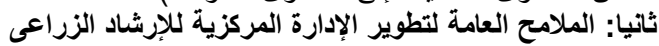

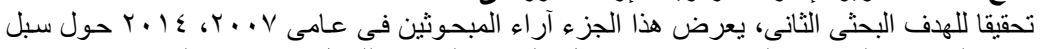

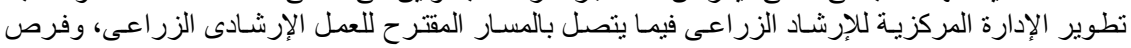

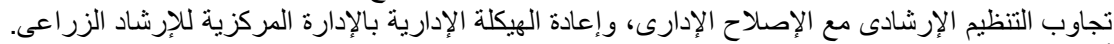

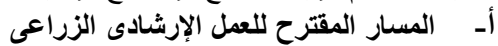

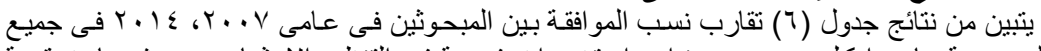

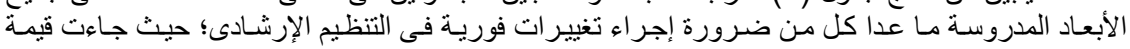

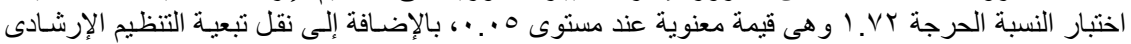

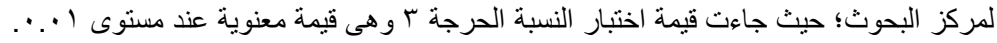

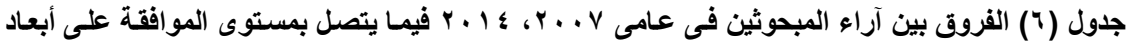

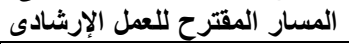

\begin{tabular}{|c|c|c|c|c|c|c|}
\hline \multicolumn{2}{|c|}{ معنوية الفروق } & \multirow{2}{*}{ الفزوق بين } & \multicolumn{2}{|c|}{ مستوى الموافقة (\%) } & \multirow{2}{*}{ أبعاد المسار المقترح للعمل الإرشادى } & \multirow{2}{*}{ p } \\
\hline$r+1 \leq$ & $r \cdot r$ & & قياس عام & 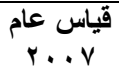 & & \\
\hline \multirow[t]{8}{*}{$\sqrt{ }$} & & *I. VY & $0 \wedge . \varepsilon$ & ro.r & إجر اء تغيير ات فورية فى التنظيم & 1 \\
\hline & $\sqrt{ }$ & 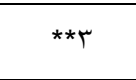 & rT.l & $T \leqslant . V$ & نقل تبعية التنظيم الإرشادى لمركز & r \\
\hline & & $\cdot \leqslant 1$ & $\wedge \wedge . \wedge$ & $1 \ldots$ & تضمين الأنشطة الإرشادية أنشطة التشية & r \\
\hline & & 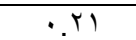 & Vo. 0 & $v \cdot .7$ & البحث عن مصادر جديدة للتمويل. & $\varepsilon$ \\
\hline & & $.1 \leqslant$ & $\wedge \leqslant . \vee$ & $\Lambda \Lambda . r$ & التوسع فى الأهداف الإرشادية & 0 \\
\hline & & $\cdot(1)$ & v.l & 0.9 & إضافة مهام جديدة للعمل الإرشادى & 7 \\
\hline & & $\cdot Y \leqslant$ & NY.r & $\Lambda \Lambda . Y$ & ضم جمهور إرشادى زر اعى جديد. & $\mathrm{V}$ \\
\hline & & $.1 \varepsilon$ & Vq.Y & Nr.乏 & تجريب مداخل إرشادية جديدة. & $\wedge$ \\
\hline
\end{tabular}

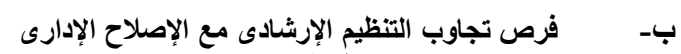

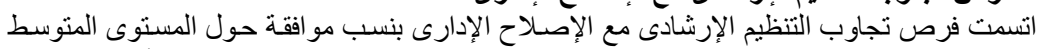

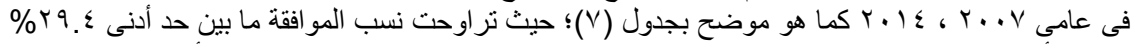

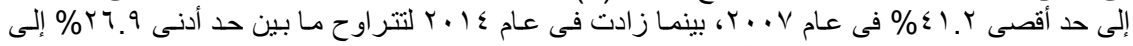

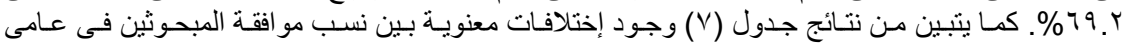

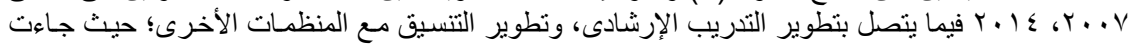

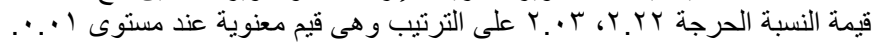


Kassem, H. S.

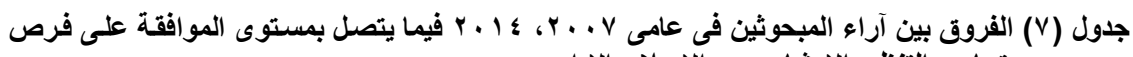

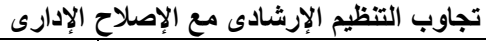

\begin{tabular}{|c|c|c|c|c|c|c|}
\hline \multicolumn{2}{|c|}{ معنويةٌ الفروق } & \multirow{2}{*}{ الفروق بين } & \multicolumn{2}{|c|}{ مستوى الموافقة (\%) } & \multirow{2}{*}{ أبعاد تجاوب التظظيم الإرشادى مع الإصلاح } & \multirow[b]{2}{*}{ p } \\
\hline T. & $r \cdot v$ & & 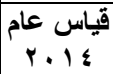 & قياس عام & & \\
\hline & & $\cdot r$ & rᄉ. & ro.r & تطوير المهام الإرشادية. & 1 \\
\hline & & .10 & $r \cdot . v$ & rq.ร & تطوير مكانة الإدارة فى الهيكل التنظيمى. & $r$ \\
\hline & & $1.1 \mathrm{~V}$ & $0 V .7$ & $\sum 1 . Y$ & تطوير مجالات وموضوعات الأنشطة الإرشادية. & $r$ \\
\hline$\sqrt{ }$ & & **Y.YY & 79.1 & ro.r & تطوير التدريب الإرشادى. & $\varepsilon$ \\
\hline & & $\cdot r$ & Y7.9 & Yq. & تطوير نظم التحفيز. & 0 \\
\hline$\sqrt{ }$ & & ${ }^{* *}{ }^{\prime} . \cdot r$ & or.1 & rq. & تطوير التنسيق مع المنظمات الأخرى. & 7 \\
\hline
\end{tabular}

ج- إعادة الهيكلة الإدارية

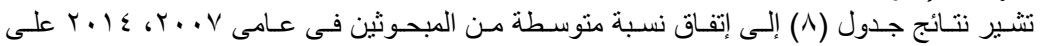

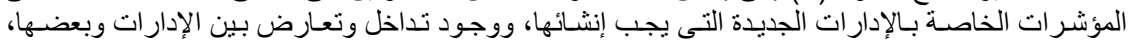

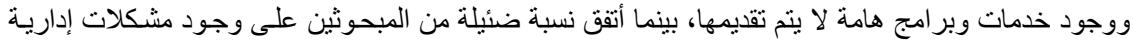

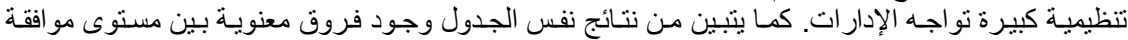

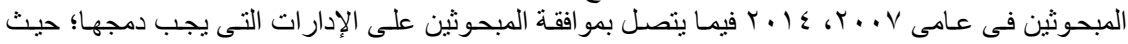

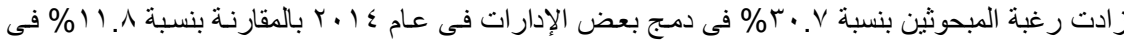

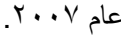

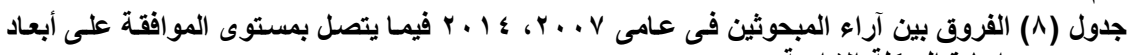
إعادة الهيكلة الإدارية آراعبة

\begin{tabular}{|c|c|c|c|c|c|c|}
\hline \multicolumn{2}{|c|}{ معنوية الفروق } & \multirow{2}{*}{ الفروق بين النسبنين } & \multicolumn{2}{|c|}{ مستوى الموافقة (\%) } & \multirow{2}{*}{ أبعاد إعادة الهيكلة الإدارية } & \multirow{2}{*}{ p } \\
\hline$r .1 \leq$ & $r . . v$ & & 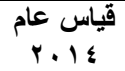 & قياس عام & & \\
\hline & & $\because .9$ & $\varepsilon Y . r$ & $\sum 1 . Y$ & إدار ات جديدة يجب إنشائها. & 1 \\
\hline \multirow[t]{4}{*}{$\sqrt{ }$} & & $* * V . \mu Y$ & $r \cdot . v$ & 11.1 & 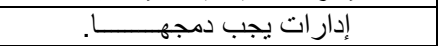 & $r$ \\
\hline & & $\because V Y$ & r^.乏 & $\varepsilon \vee .1$ & تداخل وتعارض بين الإدار ات وبعضها. & $r$ \\
\hline & & $1 . \leqslant 9$ & r.. & $1 V .7$ & وجود مشكلات إدارية وتنظيمية تواجه الإدارة. & $\varepsilon$ \\
\hline & & $\cdot . \leqslant \wedge$ & $\leq 7.1$ & or. 9 & خدمات وبر امج أساسية وهامة لا يتم & 0 \\
\hline
\end{tabular}

وبصفة عامة يتبين من النتائج السـابقة ذات الصلة بـالملامح العامـة لتطوير الإدارة المركزيـة للإرشـاد

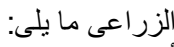

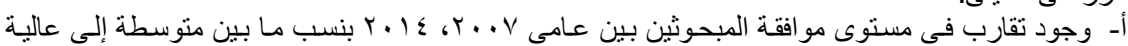

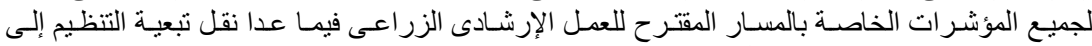

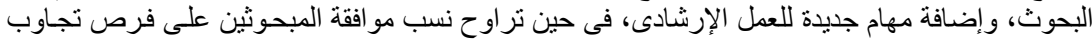

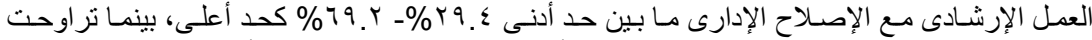

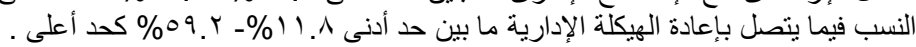

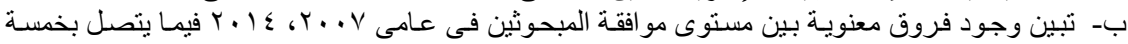

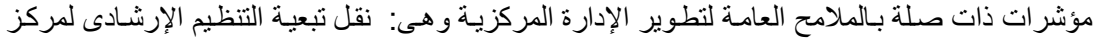

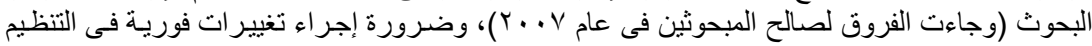




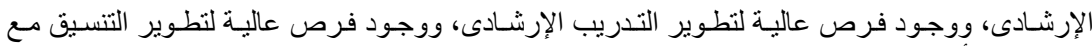

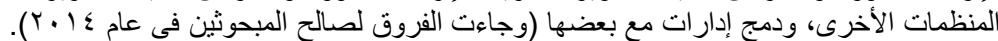

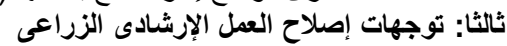

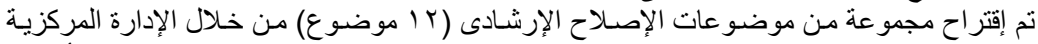

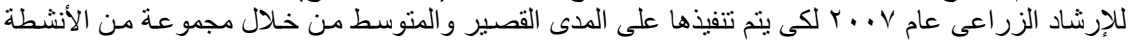

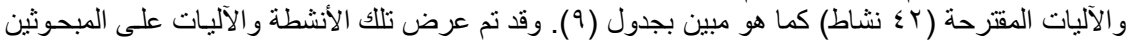

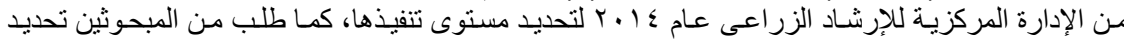

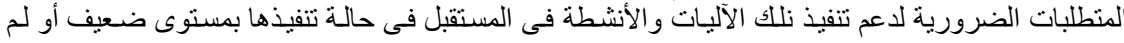

وتشير البيانات الواردة بجدول (9) أن خمسة أنشطة بنسبة $9.11 \%$ (1) من إجمالى الأنشطة تم تنفيذها

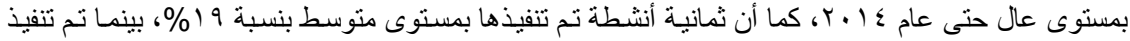

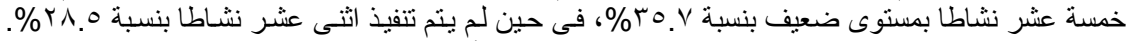

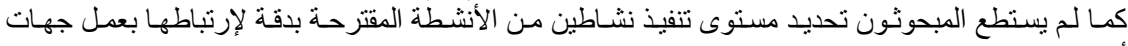

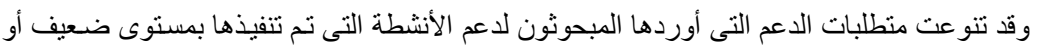

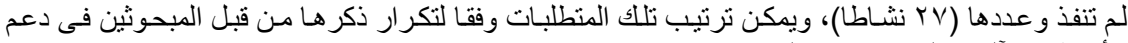
الأنشطة والآليات المقترحة كما بلئي:

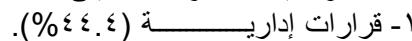

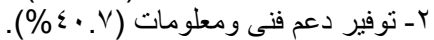

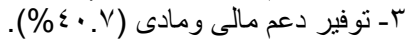

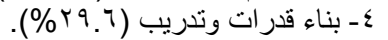

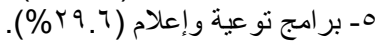

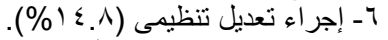

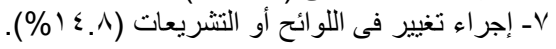


Kassem, H. S.

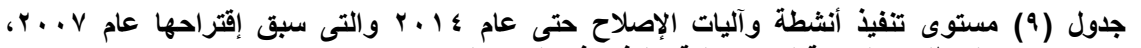
والمتطلبات اللازمة لاعم عملية تنفيذها في الإهلي المستقبل

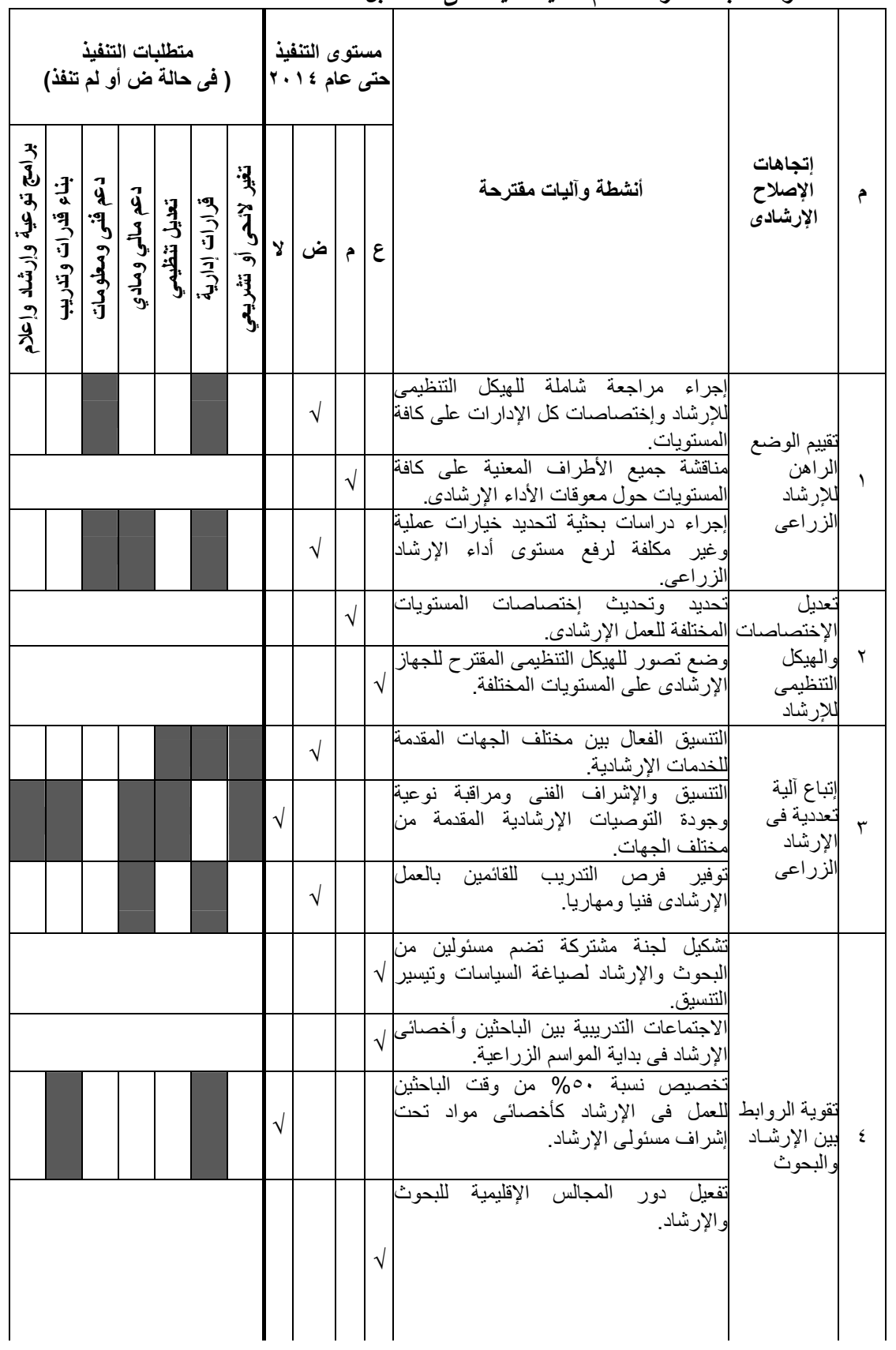




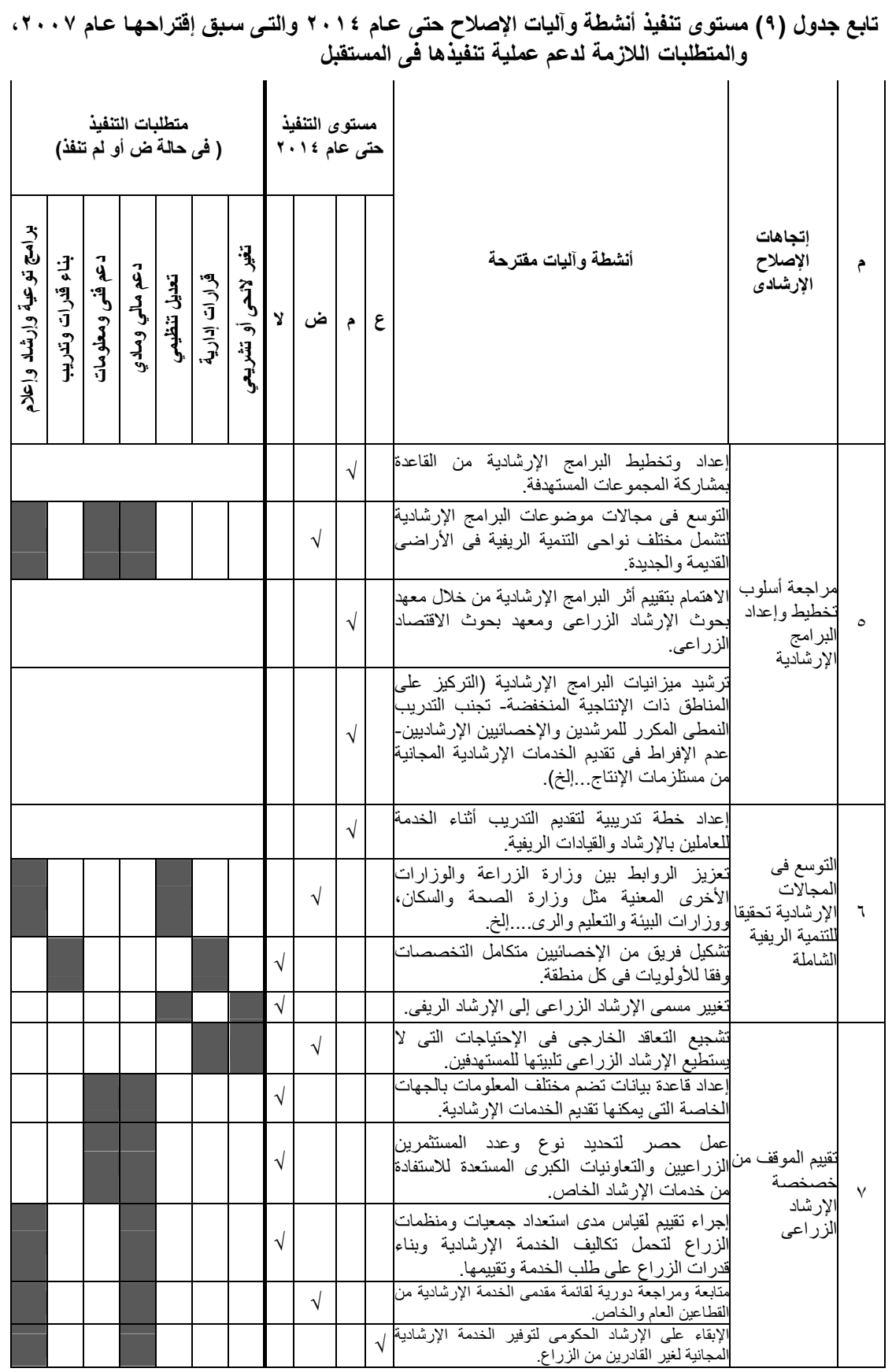


Kassem, H. S.

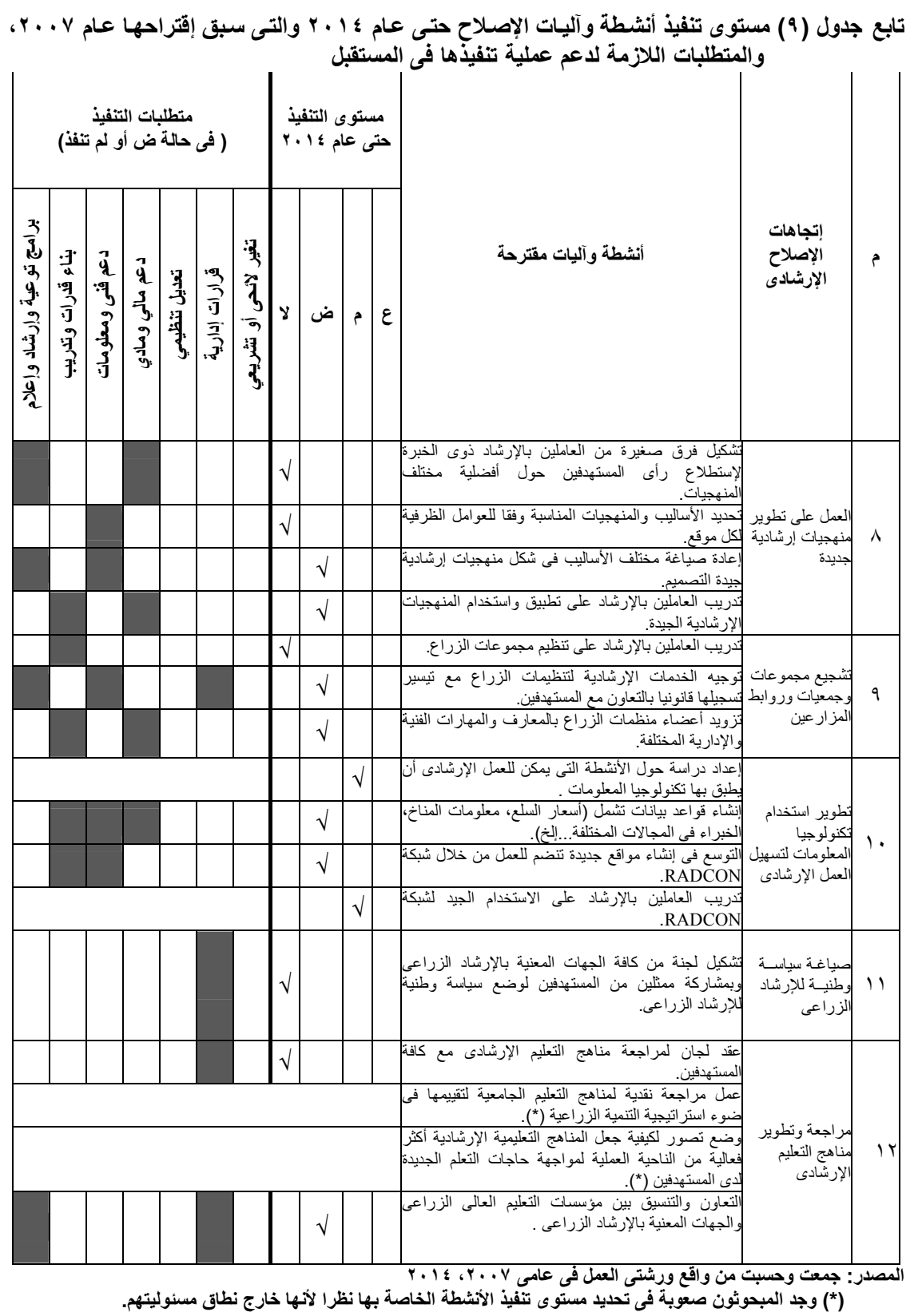


الإستنتاجات الرئيسية

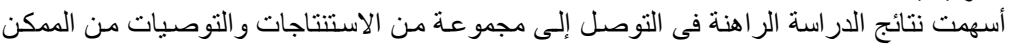

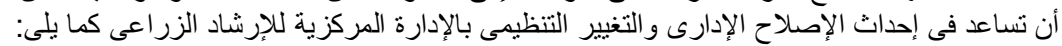

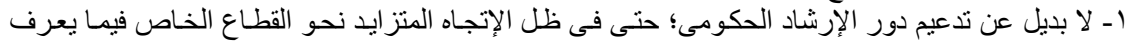

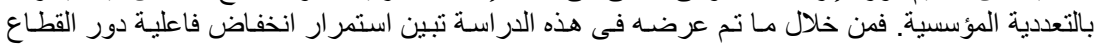

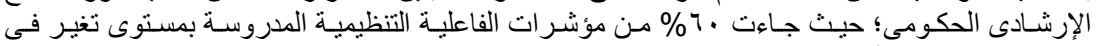

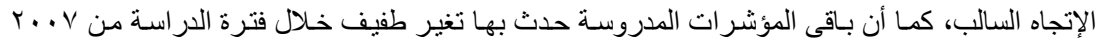

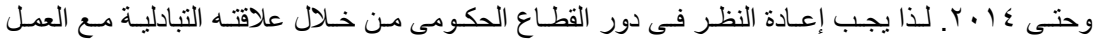

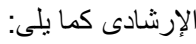

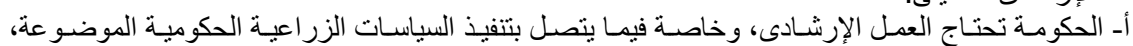

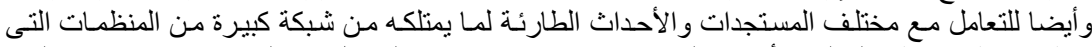

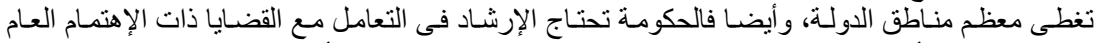

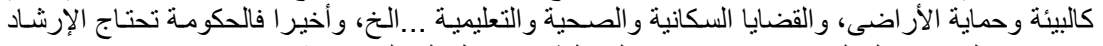

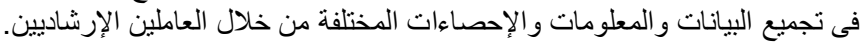

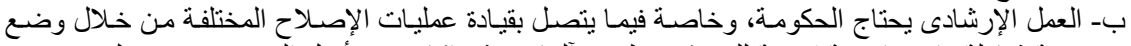

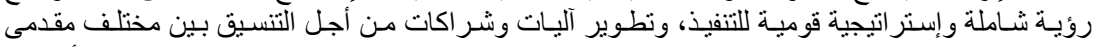

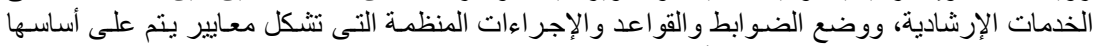

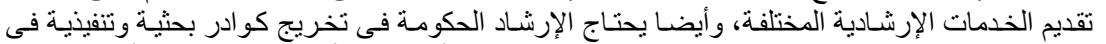

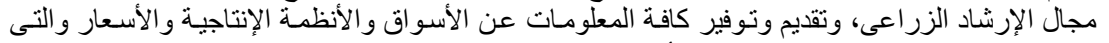

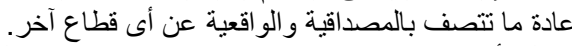

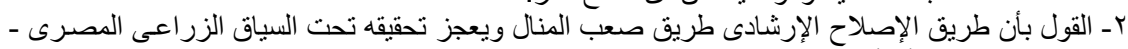

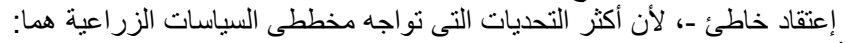

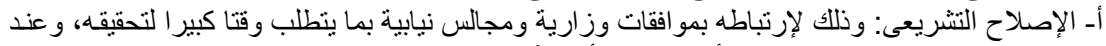

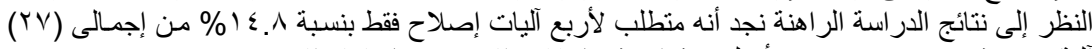

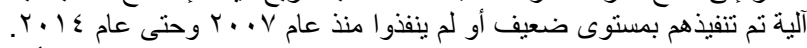

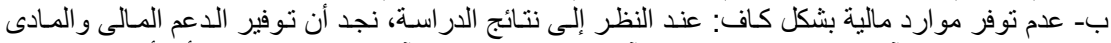

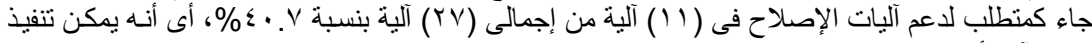

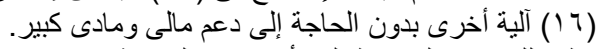

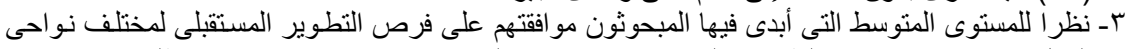

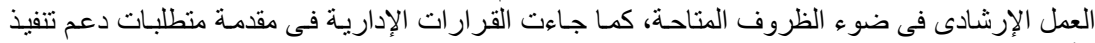

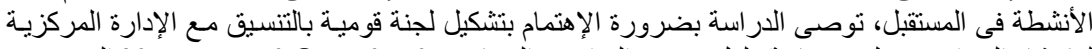

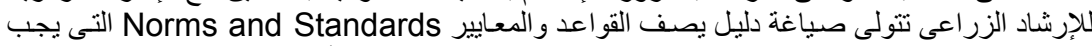

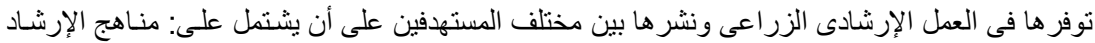

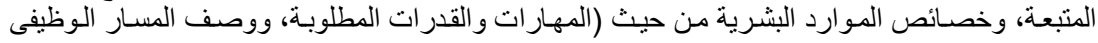

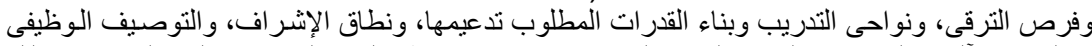

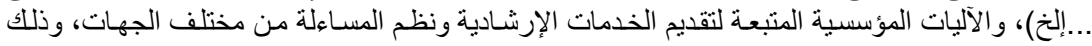

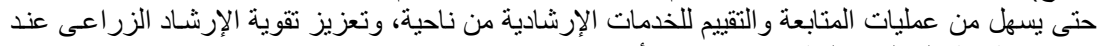

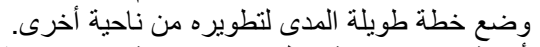

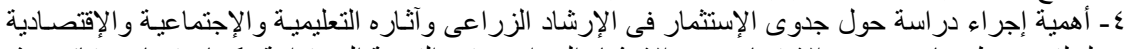

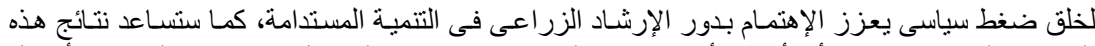

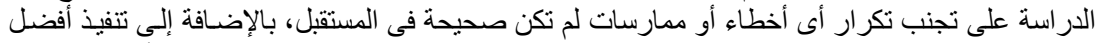

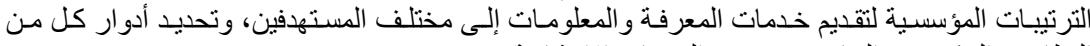
القطاعين الحكومى والخاص فى تقديم الخدمات الإرشادية. 


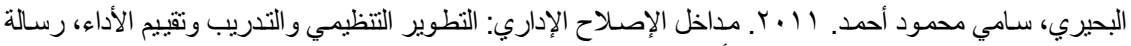

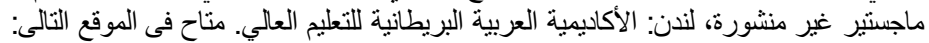

http://www.abahe.co.uk/files/Arab\%20Researchers/Arab\%20Researchers-13-112012/entrances-to-the-administrative-reform.pdf

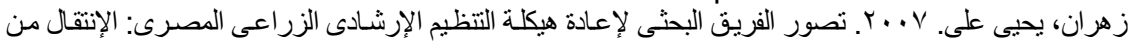

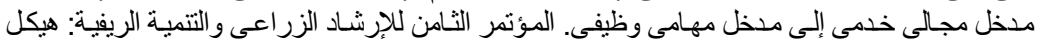

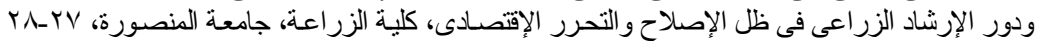

نوفمبر.

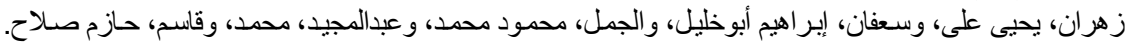

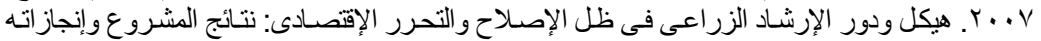

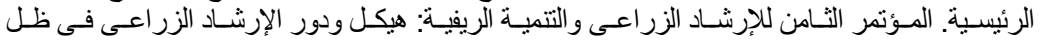

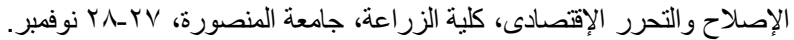

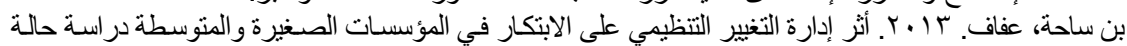

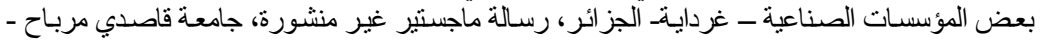

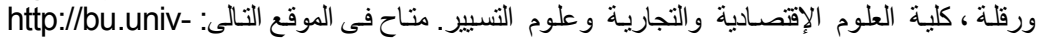
ouargla.dz/master/pdf/master_Bensaha_Afaf.pdf?idmemoire=874

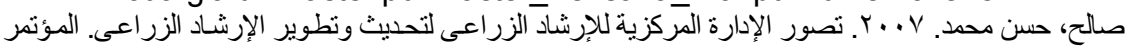

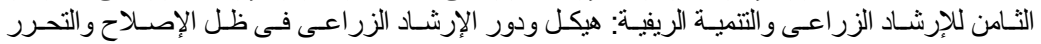

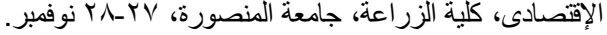

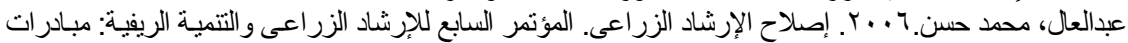

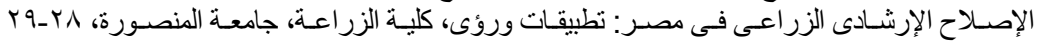

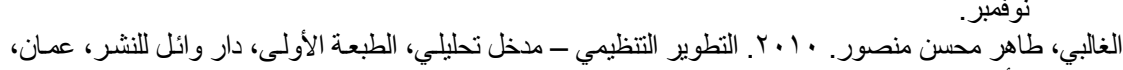
الأردن.

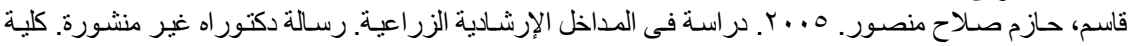

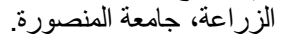

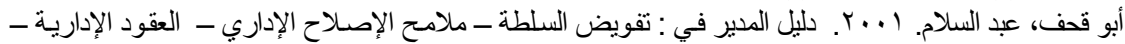

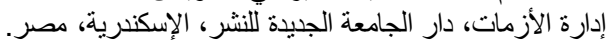

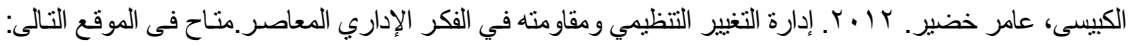
http://professors.nauss.edu.sa/dr-akkebesy/wpcontent/uploads/sites/4/4.pdf

Anderson, J. R. 2007. Agricultural advisory services. Background paper for the World Development Report 2008. Agriculture and Rural Development Department. Washington, D.C.: World Bank.

Birner, R., Davis, K. , Pender, J., Nkonya, E., Anandajayasekeram, P., Ekboir, J., Mbabu, A., Spielman, D., Horna, D., Benin, S. and Cohen, M. 2006. From best practice to best fit: A framework for analyzing pluralistic agricultural advisory services worldwide. IFPRI Discussion paper No. 37. Washington D.C.: International Food Policy Research Institute.

Birner, R., Sekher,M. and Raabe,K. 2012. Reforming the public administration for food security and agricultural development: Insights from an empirical study in Karnataka. IFPRI Discussion paper 01175. Washington D.C.: International Food Policy Research Institute. 
Feder, G., Birner, R. and Anderson, J. R. 2011. The private sector's role in agricultural extension systems: Potential and limitations. Journal of Agribusiness in Developing and Emerging Economies. 1 (1): 31-54.

Raabe, K. 2008. Reforming the agricultural extension system in India: What do we know about what works where and why?. IFPRI Discussion paper 00775. Washington D.C.: International Food Policy Research Institute.

Rajulton, F. 2001. The Fundamentals of longitudinal research: An Overview. Special Issue on Longitudinal Methodology, Canadian Studies in Population. 28(2), 2001:169-185.

World Bank. 2007. Agriculture for development. World Development Report 2008. Washington, D.C.: The International Bank for Reconstruction and Development/World Bank.

\title{
ADMINISTRATIVE REFORM AND ORGANIZATIONAL CHANGE AT AGRICULTURAL EXTENSION ORGANIZATIONS: A LONGITUDINAL STUDY OF CENTRAL ADMINISTRATION OF AGRICULTURAL EXTENSION \\ Kassem, H. S. \\ Agric. Extension and Rural Society Dept., Faculty of Agric., Mansoura Univ., Egypt
}

\begin{abstract}
The current study aims at measuring the change and developmental trends of Central Administration of Agricultural Extension (CAAE), Egypt during the period (2007-2014). Longitudinal study was used for designing data collection by following cohort type. Data were collected from the directors and deputy directors of the administrations of (CAEE) by a workshop on October 2007 and conducted again on December 2014 for the same population with different sample. Twenty four directors had attained a workshop on 2007, whereas twenty sixth on 2014. Frequencies, percentages, arithmetic mean, annual change rate (\%), critical ratio (CR) were used as statistical tools and for presenting the results. Respondents were asked during the two workshops to determine the availability level of organizational effectiveness indicators of CAAE, their acceptance level for opportunities of developing agricultural extension work, and reform mechanisms needed for promoting extension services.

The findings indicated that (10) of organizational effectiveness indicators have been changed in a positive way from 2007 to 2014, while (15) indicators have been changed in a negative way. Also, there are significant differences between the directors' acceptance level on 2007, 2014 regarding to five indicators as follows: necessity of conducting immediate changes on extension organization, CAEE's subsidiarity to agricultural research center (ARC), high opportunity for developing training, high opportunity for developing the coordination between CAEE and other organizations, and merging administrations with others. Only $11.9 \%$ for the reform mechanisms which have been suggested on 2007 were highly implemented on 2014, whereas $35,7 \%$ of them were weakly implemented.
\end{abstract}

